\title{
Utilizing natural helpers to enhance a community's capacity and competence using the PIECES $®$ model of health promotion
}

\begin{abstract}
Health Promotion is an emerging field of interest seeking a unified definition of purpose and structural implementation. Incorporating the utility of the PIECES $®$ model into health promotion efforts involving natural helper strategies will provide a consistent, comprehensive structure upon which programs can evolve. The model's simplicity lends itself to common-sense application and minimal training, which is a critical component when developing natural helpers for health promotion initiatives. The model also allows for retaining a flexible approach to health promotion which is often necessary when addressing individual variances. Additionally, it is rigid enough to retain structural integrity when applied to general populations where the need for scalability is required.
\end{abstract}

Volume 2 Issue I - 2015

\author{
Mary Ellen Rose \\ Subject matter specialist, University of Wisconsin MOOC, USA \\ Correspondence: Mary Ellen Rose, Subject matter specialist, \\ University of Wisconsin MOOC, 13505 Straw Bale Lane, \\ Darnestown, MD 20878, 369 Essex Ave, Gloucester, MA 01930 \\ USA, Tel 2404767673, Email merosephd@travelhealthy.org
}

Received: December 04, 2014 | Published: February 03, 2015

Keywords: PIECES $®$ model, IIHP model

Abbreviations: IIHP, international institute for health promotion

\section{History}

The PIECES ${ }^{\circledR}$ model (Figure 1) was influenced by the work of two health institutions, the World Health Organization and American University's International Institute of Health Promotion. Established in 1948, The World Health Organization, declared a constitutional objective of attaining the highest possible level of health for all peoples. It later specifically defined health promotion as "the process of enabling people to increase control over, and to improve, their health". ${ }^{1}$ In 1994, the International Institute for Health Promotion (IIHP) was established as an addition to the National Center for Health Fitness at American University. The IIHP assists in leading, facilitating, and coordinating the efforts of many international individuals and organizations as well as serving as a global center for the development and advancement of health promotion policies, programs, services and research efforts.

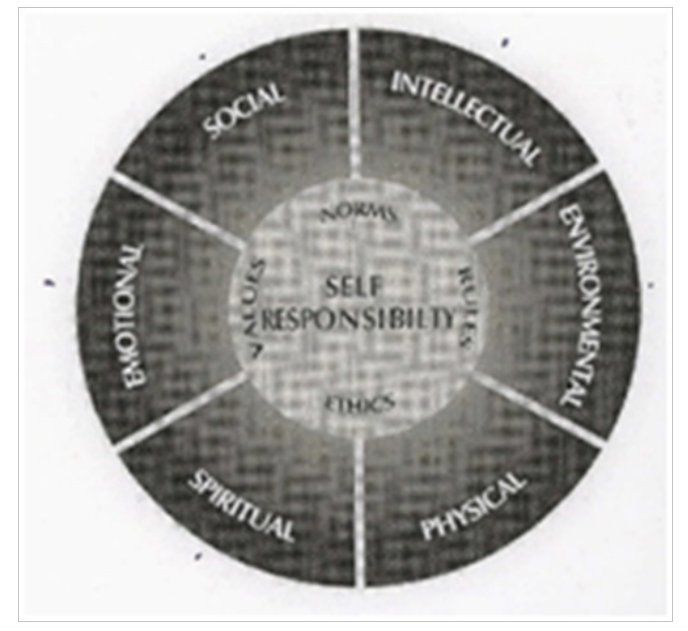

Figure I PIECES ${ }^{\circledR}$ model.
The IIHP developed a model representing the constructs of optimal wellness which is predicated upon the notion that significant contributors to optimal wellness include physical, spiritual, emotional, social, intellectual and environmental health. Defined by their norms, rules, values and ethics, the individual is central to the designation of responsibility for optimal wellness in this model. The IIHP model is an example of an individual-basis model. Health promotion theory has also introduced models with a social-basis. Ecological Models of health behavior, propose that behaviors are influenced by intrapersonal, sociocultural, policy and physical-environmental factors which are likely to interact. ${ }^{2}$ Despite the introduction of several other health promoting models and theories, transcribing these models and theories into comprehensive, interdisciplinary practice continues to challenge health promotion practitioners. The efficacy of health promotion initiatives in the future will depend not only upon the consequence of the message being delivered to the public, but it will also be contingent upon the public's ability to cognitively process the message at a level of understanding that will lead to positive action and long term change. The message must be comprehensive and practical at its very basis

In addition to speaking to the individual, health promotion should use effective communication to appropriately implement globally operative initiatives aimed at improving the health and wellness of all. A critical consideration of health promotion theory and model development involves addressing issues surrounding literacy, access and responsibility. Even if we accept the notion that the individual retains some degree of choice and control over health behaviors through the imposition of personal responsibility, the efficacy of those chosen actions are still dependent upon limitations presented by access and literacy concerns. Individuals are subject to the larger impact of humanity and the environment and that fact cannot be ignored.

\section{Model development}

Acknowledging the constructs within the ecological models of health behavior and adopting the health tenets IIHP attributes to optimal wellness, the PIECES ${ }^{\circledR}$ model of health promotion 
presents a system that is informed by the multi-level perception offered by ecological perspectives and theories addressing both an individual and social basis. PIECES ${ }^{\circledR}$ is an acronym representing six categories of health influencers (Physical, Intellectual, Emotional, Community, Environmental and Spiritual) which were verified through an international study to be essential components of global health promotion. ${ }^{3}$ The intra personal section of the PIECES ${ }^{\circledR}$ model addresses physical health, intellectual health and emotional health, while the inter personal section addresses social and community health. The ecological section addresses environmental health, while the final section, represented by introspection, addresses spiritual health. These six constructs comprise a model which presents a starting point from which design and assessments can be derived by health promotion practitioners in the establishment and analysis of practical initiatives that can then be taught to natural helpers.

The PIECES ${ }^{\circledR}$ model represents the impact Physical, Intellectual, Emotional, Community, Environmental and Spiritual component variables represent to the optimal wellness of the individual or global population of humanity. In order to adequately influence optimal wellness however, developing a model is not a comprehensive solution-it is simply a tool to be utilized by the practitioners of health promotion.

\section{Natural Helpers}

Because some studies have shown that routine intervention facilitated by health professionals alone, may actually weaken the community's natural support systems and mutual help organizations, the natural helper intervention for the utilization of this model presents a suitable match for efficacy. ${ }^{4}$ The natural helper intervention model is credited within social ecological models seeking to affect wellbeing deportment and has been found to positively influence health behaviors. ${ }^{5}$ Natural helpers function within a community to provide informal, spontaneous assistance in the form of social support, information distribution, advice, tangible aid and referrals to extended resources. Defined as individuals with knowledge contributing to the capacity and competency of their community's health, the natural helper operates within person-centered webs of relationships that connect individuals to other individuals or groups. ${ }^{4}$

\section{Process}

The PIECES ${ }^{\circledR}$ model presents a user-friendly acronym to denote a complex utilization of constructs determined to impact the health of individuals and their global neighbors. Incorporating a flexible posture toward implementation and broad definitions of the six constructs, the PIECES $\AA$ model can be utilized by natural helpers in both formal and informal health intervention opportunities.

\section{Intrapersonal needs}

If the assurance of basic physical needs of an individual can be met; that is nutritious food, clean water, appropriate shelter and basic medical care, then efforts to advance health promotion concerns forward toward addressing intellectual health issues can be realized. These secondary or intellectual issues include education, literacy and ensuring the cognitive understanding of why physical health is important. Using effective pedagogy to advance the message of health promotion, the individual is then capable of moving forward into the complexity of addressing emotional health challenges. Realizing that emotions can overwhelm the ability or desire to consider the role of health and wellness, we must seek to empower the perception of control through a sincere recognition of the critical nature emotional health plays in optimal wellness and health promotion.

\section{Interpersonal reciprocity}

At this point, because we have addressed the unique intra personal constructs of the population, we can now speak to the role of community health. Within this element the reciprocal relationship of responsibility and accountability exists between the individual and others. This relationship cannot be denied and it must be a critical consideration of health promotion efforts. That being understood, the same reciprocal relationship of responsibility and accountability that exists between the individual and others is also present in environmental health considerations. Individuals are not independent of their environment just as environmental outcomes are not independent of the impact presented by the presence of an individual or a general population. Indeed much of the status realized in the natural and synthetic environment is dependent upon human construction and consumption.

\section{Introspective element}

Finally, there is the issue of spiritual health. Variables within this category have been delimited to cultural norms, rules values, ethics and a global perspective of the self. The acknowledged designation of a scientific or theological interpretation of spirituality is secondary to the acceptance of the role of spiritual health. It is imperative that we comprehend and accept the fact that we are a part of something larger than ourselves and our immediate milieu. The acknowledgment of spiritual health issues is equally critical to understanding the concept of global health as we now understand the global implications of a single disease state that is occurring continents away. A personal grasp of the global health concept as defined by the spiritual element of the PIECES ${ }^{\circ}$ model represents the most critical reciprocal relationship of responsibility and accountability that exists in health promotion.

\section{Summary}

When formulating an objective for global health promotion, one might consider the following statement proposed when the PIECES ${ }^{\circledR}$ model was in its early stages of development.

The individual's responsibility and inclination toward contributing to global health and wellness is dependent upon the resolution of the community, state and nation to first empower that individual to maximize the objective of attaining personal health goals. To this end, we, as a nation must ensure every man, woman and child has equal access to the institutions and education which serve to empower individual responsibility toward social, intellectual, environmental, physical, spiritual and emotional health practices that are consistent with the personal norms, values, rules and ethics of their individual culture. ${ }^{6}$

Given the structure and simplicity defining each of the six health constructs defined by the PIECES ${ }^{\circledR}$ model, natural helpers can be trained to work within this framework to discover and address the impact of singular issues on the general health status of the individual. Although the multidisciplinary nature of health promotion presents the possibility of over-complicating the sublime ability of natural helpers to engage peers toward better health, utilizing the PIECES ${ }^{\circledR}$ model may serve as a stepping stone in the direction of common-sense solutions for future health promotion efforts. 


\section{Acknowledgements}

None.

\section{Conflict of interest}

The author declares no conflict of interest.

\section{References}

1. World Health Organization (WHO). Milestones in Health Promotion: Statements from Global Conferences. Switzerland: World Health Organization Press; 2009.

2. Sallis JF, Owen N. Ecological Models of Health Behavior. In: Glanz K, et al. editors. Health Behavior and Health Education: Theory, Research, and Practice. 3rd ed. USA: Wiley, John \& Sons, Incorporated; 2002. p. $462-484$.
3. Rose ME. Advancing a transdisciplinary representation of wellbeing for global health promotion. China: HKUL Electronic Resources; 2003.

4. Eng E, Smith J. Natural helping functions of lay health advisers in breastcancer education. In: DiClemente RJ, et al. editors. Emerging Theories in Health Promotion Practice and Research. 2nd ed. USA: Jossey-Bass; 1995.

5. Best A, Stokols D, Green LW, et al. An integrative framework for community partnering to translate theory into effective health promotion strategy. Am J Health Promot. 2003;18(2):168-176.

6. Rose ME. Global Health Promotion ideas and systems. USA: American University; 2003. 